\title{
Effect of growth hormone treatment on children with idiopathic short stature and idiopathic growth hormone deficiency
}

Minji Im, MD', Yong-Dae Kim, MD², Heon-Seok Han, MD ${ }^{1}$

Departments of ${ }^{1}$ Pediatrics and ${ }^{2}$ Preventive Medicine, Chungbuk National University Hospital, Chungbuk National University College of Medicine, Cheongju, Korea
Received: 30 March, 2017

Revised: 19 April, 2017

Accepted: 12 May, 2017

Address for correspondence:

Heon-Seok Han, MD.

Department of Pediatrics, Chungbuk National University Hospital, Chungbuk National University College of Medicine, 776 1(il)sunhwan-ro, Heungdeok-gu, Cheongju 28644, Korea

Tel: +82-43-269-6370

Fax: +82-43-264-6620

E-mail:hshan@chungbuk.ac.kr

https://orcid.org/0000-0003-00122545
Purpose: There are inconsistencies in the results reported in a small number of previous studies into growth hormone $(\mathrm{GH})$ treatment in Korean children with idiopathic short stature (ISS) and idiopathic growth hormone deficiency (IGHD). Thus, the authors retrospectively compared the effects of GH in ISS and IGHD.

Methods: From the medical records of 26 ISS and 30 IGHD children, auxological and biochemical changes including chronologic age (CA), bone age (BA), height standard deviation score (HT-SDS), predicted adult height (PAH), midparental height (MPH), insulin-like growth factor-1 (IGF-1), and insulin-like growth factor binding protein-3 (IGFBP-3) were compared.

Results: Before treatment, IGHD group had younger BA, lower BA/CA ratio, and lower IGF-1 level than those in the ISS group. During GH treatment, the levels of IGF-1 and IGFBP-3 were not different. Although annual BA increment was higher in IGHD group, and annual PAH-SDS increment was higher in ISS group, annual HT-SDS increments were not different. Both HT-SDS and PAH-SDS in the ISS group increased significantly until the end of the second year, and then those were not significantly different from MPH-SDS. In the IGHD group, the HT-SDS showed a significant increase till the end of the second year, and the PAH-SDS was not significantly changed at each year, but both HT-SDS and PAH-SDS were not significantly different from MPH-SDS at the end of the third year.

Conclusion: During GH treatment, both HT-SDS and PAH-SDS approached the genetic target range of MPH-SDS after 2 years in ISS children and 3 years in IGHD children.

Keywords: Growth hormone, Idiopathic short stature, Growth hormone deficiency

\section{Introduction}

With a sufficient supply of growth hormone (GH), obtained via recombinant DNA technology, clinicians can treat children with growth hormone deficiency (GHD), as well as those with other non-GH deficient disorders. Short stature is defined as a height of less than -2 standard deviations (SDs) compared to the average height at the corresponding sex and age ${ }^{1)}$. Idiopathic short stature (ISS) is a short stature condition in subjects with a normal birth weight, normal body proportions, normal GH secretion, and no specific cause for their short stature ${ }^{2,3)}$. However, ISS subjects are a heterogeneous group of children with many unidentified causes of short stature. Children with familial short stature and constitutional delay of growth and puberty are included in the ISS category ${ }^{4)}$. After the 2003 approval by the U.S. Food and Drug Administration of the use of GH for children with a height SD score (HT-SDS) of less than -2.25 and a short predicted adult height (PAH), clinical interests in GH treatment for ISS children increased ${ }^{5}$. There have been several clinical reports comparing GH 
treatment effects on children with ISS and those with GHD, but there are few such reports for Korean subjects, and the results presented in those reports have been inconsistent ${ }^{6-8)}$. With those inconsistencies in mind, the authors compared the growthpromoting effects of $\mathrm{GH}$ in both idiopathic GHD (IGHD) and ISS subjects by retrospectively reviewing medical records.

\section{Materials and methods}

\section{Subjects}

We reviewed retrospectively the medical records of short statured children who were treated with GH between March 2002 and March 2016. Subjects with chromosomal abnormalities, organic brain lesions, systemic diseases, or syndromes that result in growth disorders were excluded. All included subjects had a normal birth weight. Among the 56 short statured children, conventional GH provocation tests using insulin and glucagon were performed in order to classify them as either GHD or ISS. Normal GH response at the test was defined as a peak stimulated GH level above $10 \mathrm{ng} / \mathrm{mL}$. If the GHD subject's brain magnetic resonance images appeared normal, the diagnosis was IGHD.

\section{Methods}

During GH treatment, auxological and biochemical parameters including bone age (BA), insulin-like growth factor-1 (IGF-1), and insulin-like growth factor binding protein-3 (IGFBP-3) were recorded every 6 months. BA was evaluated by using the Greulich-Pyle method ${ }^{9}$, while PAH was calculated by applying the Baily-Pinneau method ${ }^{10)}$. Midparental height (MPH) was the average height of the parents plus $6.5 \mathrm{~cm}$ in boys and minus $6.5 \mathrm{~cm}$ in girls. The HT-SDS was calculated as the children's height minus the average height for children of the same age and sex divided by the $\mathrm{SD}^{11)}$. Both MPH and PAH were calculated as SDS compared to the sex-matched adult height SD. The values of IGF-1 and IGFBP-3 were changed into age- and sex-matched SDS (IGF-1-SDS and IGFBP-3-SDS, respectively $)^{12)}$. Annual and total increment ratios of $\mathrm{BA}$ with HT-SDS, and PAH-SDS were calculated over a period of 3 years. Initially, GH treatment was provided at a dose $0.23 \mathrm{mg} / \mathrm{kg} / \mathrm{wk}$ for the IGHD subjects and $0.23-0.33 \mathrm{mg} / \mathrm{kg} / \mathrm{wk}$ for the ISS subjects. The GH dosage for the subjects with ISS was adjusted according to the subject's IGF-1 level in order not to exceed a dose greater than $+2 \mathrm{SD}$.

\section{Statistical analysis}

Statistical analyses were performed by using IBM SPSS Statistics ver. 23.0 (IBM Corp., Armonk, NY, USA). All data are expressed as mean $\pm S D$ values. Mann-Whitney $U$-test was applied to compare differences of numerical variables between the groups at each time and chi-square test or Fisher exact test was performed to compare frequencies between groups. Wilcoxon signed rank test was applied to compare differences of the variables within the groups at each time. A $P$-value of 0.05 or less was considered statistically significant; however, in multiple comparisons between all times, the Bonferroni correction was applied and a $P$-value of 0.005 or less was considered statistically significant.

\section{Results}

\section{Clinical characteristics of study population at the start of GH therapy}

Among the 56 subjects included in this study, there were more males $(n=40,71.4 \%)$ than females $(n=16,28.6 \%)$. At baseline, the mean HT-SDS for all subjects was $-2.45 \pm 0.11$, and the mean IGF-1-SDS was $-0.80 \pm 0.06$. The peak-stimulated GH level was $20.3 \pm 10.6 \mathrm{ng} / \mathrm{mL}$ and $6.6 \pm 2.5 \mathrm{ng} / \mathrm{mL}$ in children with ISS and IGHD, respectively $(P<0.001)$. Similarly, the mean IGF-I-SDS value was significantly higher in children with ISS than that in children with IGHD ( $-0.53 \pm 0.85$ vs. $-1.07 \pm 0.77 ; P=0.0018)$. The 2 groups were not different in chronologic age (CA), height, weight, body mass index, MPH-SDS, HT-SDS, and PAH-SDS. However, children with IGHD had significantly lower BA, BA/

Table 1. Clinical characteristics of ISS and IGHD subjects at the start of GH therapy

\begin{tabular}{|c|c|c|c|}
\hline Characteristic & ISS $(n=26)$ & $\operatorname{IGHD}(\mathrm{n}=30)$ & $P$-value $e^{\text {a) }}$ \\
\hline Female sex, n (\%) & $10(38.5)$ & $6(20.0)$ & 0.219 \\
\hline MPH-SDS & $-0.95 \pm 0.62$ & $-0.90 \pm 0.64$ & 0.549 \\
\hline CA (yr) & $9.41 \pm 2.65$ & $8.52 \pm 3.18$ & 0.111 \\
\hline$B A(y r)$ & $8.85 \pm 2.80$ & $7.24 \pm 3.00$ & 0.041 \\
\hline $\mathrm{BA} / \mathrm{CA}$ & $0.93 \pm 0.12$ & $0.85 \pm 0.13$ & 0.005 \\
\hline Height (cm) & $119.7 \pm 13.5$ & $114.9 \pm 15.8$ & 0.163 \\
\hline Weight (kg) & $24.2 \pm 6.5$ & $22.7 \pm 9.5$ & 0.124 \\
\hline BMI $\left(\mathrm{kg} / \mathrm{m}^{2}\right)$ & $16.6 \pm 1.7$ & $16.5 \pm 3.0$ & 0.358 \\
\hline HT-SDS & $-2.39 \pm 0.38$ & $-2.52 \pm 0.53$ & 0.379 \\
\hline PAH-SDS & $-2.90 \pm 1.40$ & $-2.20 \pm 0.80$ & 0.079 \\
\hline $\mathrm{GH}(\mathrm{mg} / \mathrm{kg} / \mathrm{wk})$ & $0.27 \pm 0.06$ & $0.24 \pm 0.03$ & 0.032 \\
\hline IGF-1 (ng/mL) & $192.29 \pm 105.28$ & $136.52 \pm 89.78$ & 0.021 \\
\hline IGF-1 SDS & $-0.53 \pm 0.85$ & $-1.07 \pm 0.77$ & 0.018 \\
\hline IGFBP-3 (ng/mL) & $2464 \pm 620$ & $2427 \pm 999$ & 0.511 \\
\hline IGFBP-3 SDS & $-0.62 \pm 0.87$ & $-0.51 \pm 1.72$ & 0.511 \\
\hline Peak GH (ng/mL) & $20.3 \pm 10.6$ & $6.6 \pm 2.5$ & $<0.001$ \\
\hline Peak GH range (ng/mL) & $11.24-38.19$ & $1.57-9.99$ & - \\
\hline
\end{tabular}

Values are presented as mean \pm standard deviation unless otherwise indicated.

ISS, idiopathic short stature; IGHD, idiopathic growth hormone deficiency; GH, growth hormone; MPH, midparental height; SDS, standard deviation score; CA, chronologic age; BA, Bone age; BMI, body mass index; HT, height; $\mathrm{PAH}$, predicted adult height; IGF1, insulin like growth factor-1; IGFBP-3, insulin like growth factor binding protein-3.

a) $P$-value obtained by chi-square test for categorical variables and Mann-Whitney U-test for numerical variables. 
CA ratio (Table 1)

\section{Changes in clinical characteristics during $\mathrm{GH}$ therapy for 3 years}

The CA, BA, BA/CA ratio, HT-SDS, PAH-SDS, IGF-1-SDS, and IGFBP-3-SDS were not significantly different between the ISS and IGHD groups after 1,2, or 3 years of GH therapy except $\mathrm{CA}$ at 3 years. The GH dosage was consistently higher in the ISS group than in the IGHD group, until the end of the second year (Table 2). In both groups, the HT-SDS increased significantly until the end of second year. As a result, the increased HT-

Table 2. Changes in clinical characteristics of ISS and IGHD subjects during $\mathrm{GH}$ treatment

\begin{tabular}{|c|c|c|c|}
\hline Characteristic & ISS & IGHD & $P$-value ${ }^{\text {a) }}$ \\
\hline At 1-yr GH & $(n=26)$ & $(n=30)$ & \\
\hline Female sex, n (\%) & $10(38.5)$ & $6(20.0)$ & 0.219 \\
\hline$C A(y r)$ & $10.38 \pm 2.61$ & $9.55 \pm 3.20$ & 0.165 \\
\hline$B A(y r)$ & $9.72 \pm 2.82$ & $8.78 \pm 3.21$ & 0.180 \\
\hline $\mathrm{BA} / \mathrm{CA}$ & $0.93 \pm 0.11$ & $0.91 \pm 0.09$ & 0.398 \\
\hline HT-SDS & $-1.79 \pm 0.48$ & $-1.96 \pm 0.65$ & 0.687 \\
\hline PAH-SDS & $-1.90 \pm 1.16$ & $-1.94 \pm 0.95$ & 0.812 \\
\hline $\mathrm{GH}$ (mg/kg/wk) & $0.26 \pm 0.05$ & $0.23 \pm 0.02$ & 0.005 \\
\hline IGF-1-SDS & $0.16 \pm 0.78$ & $0.52 \pm 1.46$ & 0.593 \\
\hline IGFBP-3-SDS & $0.79 \pm 1.73$ & $0.92 \pm 2.13$ & 0.800 \\
\hline At 2-yr GH & $(n=19)$ & $(n=28)$ & \\
\hline Female sex, n (\%) & $7(36.8)$ & $6(21.4)$ & 0.408 \\
\hline$C A(y r)$ & $11.32 \pm 2.51$ & $10.55 \pm 3.15$ & 0.135 \\
\hline$B A(y r)$ & $10.96 \pm 2.76$ & $10.07 \pm 3.29$ & 0.267 \\
\hline $\mathrm{BA} / \mathrm{CA}$ & $0.96 \pm 0.08$ & $0.95 \pm 0.08$ & 0.398 \\
\hline HT-SDS & $-1.40 \pm 0.56$ & $-1.66 \pm 0.67$ & 0.688 \\
\hline PAH-SDS & $-1.47 \pm 0.99$ & $-1.80 \pm 1.04$ & 0.313 \\
\hline $\mathrm{GH}$ (mg/kg/wk) & $0.26 \pm 0.06$ & $0.23 \pm 0.02$ & 0.048 \\
\hline IGF-1 SDS & $0.55 \pm 1.17$ & $0.91 \pm 1.54$ & 0.566 \\
\hline IGFBP-3 SDS & $1.61 \pm 2.11$ & $1.64 \pm 3.08$ & 0.976 \\
\hline At 3-yr GH & $(n=13)$ & $(n=22)$ & \\
\hline Female sex, n (\%) & $5(38.5)$ & $4(18.2)$ & 0.243 \\
\hline$C A(y r)$ & $12.70 \pm 2.51$ & $10.91 \pm 2.80$ & 0.034 \\
\hline$B A(y r)$ & $12.29 \pm 2.71$ & $10.73 \pm 3.09$ & 0.130 \\
\hline $\mathrm{BA} / \mathrm{CA}$ & $0.96 \pm 0.05$ & $0.98 \pm 0.07$ & 0.533 \\
\hline HT-SDS & $-1.24 \pm 0.65$ & $-1.55 \pm 0.67$ & 0.335 \\
\hline PAH-SDS & $-1.19 \pm 0.80$ & $-1.66 \pm 0.95$ & 0.906 \\
\hline $\mathrm{GH}(\mathrm{mg} / \mathrm{kg} / \mathrm{wk})$ & $0.25 \pm 0.04$ & $0.23 \pm 0.02$ & 0.129 \\
\hline IGF-1 SDS & $0.84 \pm 0.94$ & $0.83 \pm 1.37$ & 0.251 \\
\hline IGFBP-3 SDS & $1.73 \pm 2.50$ & $2.47 \pm 2.18$ & 0.431 \\
\hline
\end{tabular}

Values are presented as mean \pm standard deviation unless otherwise indicated.

ISS, idiopathic short stature; IGHD, idiopathic growth hormone deficiency; GH, growth hormone; MPH, midparental height; SDS, standard deviation score; CA, chronologic age; BA, Bone age; $\mathrm{HT}$, height; PAH, predicted adult height; IGF-1, insulin like growth factor-1; IGFBP-3, insulin like growth factor binding protein-3.

${ }^{\text {a) }}$-value obtained by chi-square test or Fisher exact test for categorical variables and Mann-Whitney U-test for numerical variables.
SDS was not significantly different from the MPH-SDS at the end of the second year in the ISS group, and at the end of the third year in the IGHD group (Fig. 1). The PAH-SDS increased significantly until the end of the second year in the ISS group, but there was no significant change in PAH-SDS at each year in the IGHD group. Initial PAH-SDS statistically approached MPH-SDS at the end of the second year of GH treatment in the ISS group and the third year in the IGHD group, respectively (Fig. 2).

\section{Annual changes in growth parameters during GH therapy for 3 years}

Annual changes in the $\mathrm{BA} / \mathrm{CA}$ ratio $(\triangle \mathrm{BA} / \triangle \mathrm{CA})$ were significantly greater in the IGHD group than in the ISS group over the full 3-year treatment period as well as after 1,2, and 3 years of GH therapy. However, full term and annual changes in the $\triangle$ HT-SDS/ $\triangle \mathrm{CA}$ ratio were not different between the 2 groups. Annual changes in the $\triangle \mathrm{PAH}-\mathrm{SDS} / \triangle \mathrm{CA}$ ratio were greater in the ISS group than in the IGHD group during the first 2 years, but not in the third year. Over the full 3-year treatment period, $\triangle \mathrm{PAH}-\mathrm{SDS} / \triangle \mathrm{CA}$ was significantly higher in the ISS group than in the IGHD group (Table 3)

\section{Discussion}

From our analyses, the following results were obtained; (1) before GH treatment, the IGHD group had a younger BA, lower BA/CA ratio, and lower IGF-1 level than those in the ISS group; (2) during treatment, the GH dose was consistently and

Table 3. Annual changes in growth parameters of ISS and IGHD subjects during 3 years of GH therapy

\begin{tabular}{|c|c|c|c|}
\hline Variable & ISS & $\mathrm{IGHD}$ & $P$-value $e^{\text {a) }}$ \\
\hline \multicolumn{4}{|l|}{$\triangle \mathrm{BA} / \triangle \mathrm{CA}$} \\
\hline At 1st yr & $0.91 \pm 0.20$ & $1.46 \pm 0.85$ & $<0.001$ \\
\hline At 2nd yr & $1.05 \pm 0.43$ & $1.35 \pm 0.50$ & 0.002 \\
\hline At 3rd yr & $0.97 \pm 0.23$ & $1.24 \pm 0.32$ & 0.003 \\
\hline During $3 \mathrm{yr}$ & $0.96 \pm 0.20$ & $1.37 \pm 0.38$ & $<0.001$ \\
\hline \multicolumn{4}{|l|}{$\triangle \mathrm{HT}-\mathrm{SDS} / \triangle \mathrm{CA}$} \\
\hline At 1styr & $0.62 \pm 0.47$ & $0.54 \pm 0.27$ & 0.349 \\
\hline At 2nd yr & $0.31 \pm 0.42$ & $0.39 \pm 0.37$ & 0.251 \\
\hline At $3 r d y r$ & $0.20 \pm 0.30$ & $0.22 \pm 0.29$ & 0.625 \\
\hline During 3 yr & $0.44 \pm 0.27$ & $0.43 \pm 0.23$ & 0.870 \\
\hline \multicolumn{4}{|c|}{$\triangle \mathrm{PAH}-\mathrm{SDS} / \triangle \mathrm{CA}$} \\
\hline At 1styr & $1.03 \pm 0.50$ & $0.26 \pm 0.71$ & $<0.001$ \\
\hline At 2nd yr & $0.54 \pm 0.39$ & $0.19 \pm 0.48$ & 0.022 \\
\hline At 3rd yr & $0.20 \pm 0.42$ & $0.20 \pm 0.36$ & 1.000 \\
\hline During $3 \mathrm{yr}$ & $0.72 \pm 0.36$ & $0.23 \pm 0.31$ & $<0.001$ \\
\hline
\end{tabular}

Values are presented as the mean \pm standard deviation.

ISS, idiopathic short stature; IGHD, idiopathic growth hormone deficiency; $\triangle$, difference; $B$, bone age; $C A$, chronologic age; $H T$, height; SDS, standard deviation score; $\mathrm{PAH}$, predicted adult height.

${ }^{\text {a) }}$-value obtained by Mann-Whitney U-test. 


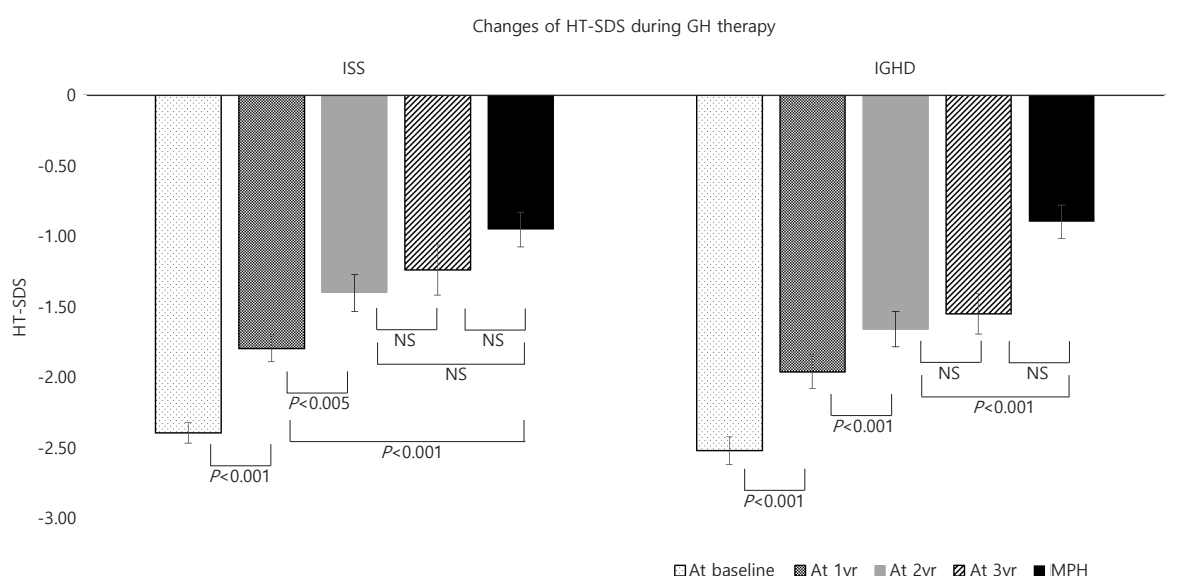

Fig. 1. Changes in height standard deviation scores (HT-SDSs) during growth hormone therapy (GH) of idiopathic short stature (ISS) and idiopathic growth hormone deficiency (IGHD) groups. Each bar represents mean \pm standard error values. Wilcoxon signed rank tests were used to compare data between each time. After applying a Bonferroni correction, a $P$-value less than 0.005 was considered significant. MPH, midparental height.

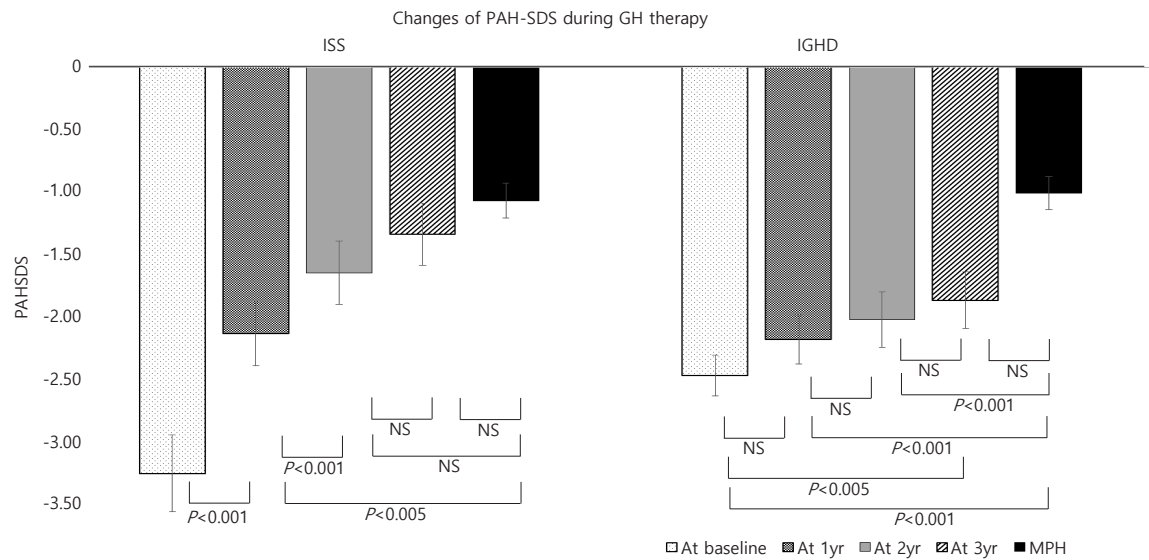

Fig. 2. Changes in predicted adult height standard deviation scores (PAH-SDSs) during growth hormone (GH) therapy of idiopathic short stature (ISS) and idiopathic growth hormone deficiency (IGHD) groups. Each bar represents mean \pm standard error values. Wilcoxon signed rank tests were used to compare data between each time. After applying Bonferroni correction, a $P$-value less than 0.005 was considered significant. MPH, midparental height.

significantly higher in the ISS group than in the IGHD group, but the levels of IGF-1 and IGFBP-3 in the two groups were not different; (3) although the annual BA increment was higher in the IGHD group and annual PAH-SDS increment was higher in ISS group, the annual HT-SDS increments were not different between the 2 groups; and (4) both HT-SDS and PAH-SDS in the ISS group increased significantly until the end of the second year, after which there was no significant difference between those and MPH-SDS. The HT-SDS in the IGHD group showed significant increases until the end of the second year, and it approached MPH-SDS at the end of the third year. The PAHSDS in the IGHD group continuously increased to approach the MPH-SDS at the end of third year. With regard to PAH-SDS, the ISS group initially appeared to grow more rapidly, compared to the growth in the IGHD group, whereas, the HT-SDS results appeared to indicate that growth in both groups was similarly.
However, we conclude this phenomenon is an optical illusion resulting from the BA difference. The baseline PAH-SDS was lower in the ISS group than in the IGHD group, but without statistical significance. This difference might have resulted in a significantly higher annual PAH-SDS increment in the ISS group during $\mathrm{GH}$ treatment, because the $\mathrm{PAH}$ calculation is sensitive to BA. The lower BA in the IGHD group resulted in a relatively higher PAH-SDS before treatment; thus, there was lower annual PAH-SDS increment during GH therapy.

Currently, the peak GH level used to differentiate GHD from ISS is $10 \mathrm{ng} / \mathrm{mL}$, although this cut-off lacks physiological support ${ }^{13)}$. Even though the CA, HT-SDS at diagnosis, and MPH in our ISS and IGHD groups were similar, those two groups are undeniably different, because the BA/CA ratio and the IGF-1SDS were significantly lower in the IGHD group than in the ISS group. 
When undergoing GH therapy, children with GHD usually attain a normal adult height, but children with ISS do not ${ }^{13,14)}$. Lee et al. ${ }^{15)}$ reported that the effect of $\mathrm{GH}$ on the final height of 25 children with GHD (14 idiopathic and 11 organic) was comparable to the target height. A similar result showing that the HT-SDS improved from -4.13 to +0.22 during 3.2 years of GH therapy with a dosage of $0.52-0.62 \mathrm{IU} / \mathrm{kg} / \mathrm{wk}$ for 35 children with GHD (13 idiopathic and 22 organic). In that study, the height at onset of puberty was associated with the improvement in final adult height ${ }^{16)}$. However, according to some Korean reports, the growth-promoting effect of GH is variable in children with ISS. The final height SDS was not markedly different from the control population in a study of familial short stature with GH treatment for more than 2 years at a dose level of $0.23 \mathrm{mg} / \mathrm{kg} / \mathrm{wk}^{6}$. Kang et al. ${ }^{7)}$ reported that HT-SDS in ISS children improved initially with a GH dose of $0.23-0.35 \mathrm{mg} / \mathrm{kg} / \mathrm{wk}$, but HT-SDS did not significantly increase after 2 years, results that were unlike those for children with GHD. However, the comparison study reported by Kim et al. ${ }^{8)}$ showed similar effects on HT-SDS in children with ISS and IGHD after 1 year of therapy with the same GH dose. A clinical trial involving children with ISS demonstrated the safety and effectiveness of GH treatment, with HT-SDS increasing from -2.39 to -1.83 with daily injections $0.37 \mathrm{mg} / \mathrm{kg} /$ wk over 6 -month periods ${ }^{17)}$. Although we do not have final adult height data for our subjects, the HT-SDS might be expected to increase to the target range during GH treatment because HT-SDS and PAHSDS approached the MPH-SDS at the end of the second and third treatment year.

The appropriate GH dose level in ISS is controversial and the effect of GH therapy may be dose-dependent. In 3 randomized controlled studies, that were increments of $0.51 \operatorname{SDS}(3.7 \mathrm{~cm})$ in adult height with GH treatment $0.22 \mathrm{mg} / \mathrm{kg} / \mathrm{wk}$ for 4.4 years ${ }^{18)}$, of 0.70 SDS $(4.3-5.0 \mathrm{~cm})$ in adult height with dose levels of $0.23-0.47 \mathrm{mg} / \mathrm{kg} / \mathrm{wk}$ for 5.9 years $^{19)}$, and of 1.23 SDS $(7.5 \mathrm{~cm})$ in female adult height with a dose of $0.42 \mathrm{mg} / \mathrm{kg} / \mathrm{wk}$ for 6.2 years ${ }^{20)}$. In the present study, we used dose levels of $0.23-0.33 \mathrm{mg} / \mathrm{kg} /$ wk, which is greater than the suggested dosage for GHD, but far below the dose levels used in previous ISS studies. The primary reason we used a relatively low dosage for the ISS children is the high cost of treatment, as the use of GH is not covered by the Korean national health insurance system. Secondarily, at the dose selected, the increased IGF-1 level in ISS group during GH therapy was thought to reflect the response of the GH-IGF-1 axis to some extent. In fact, the levels of IGF- 1 and IGFBP-3 in the ISS group did increase to positive values that were similar to those in the IGHD group. For treatment effectiveness and long-term safety, a dosing regimen of GH titrated to an IGF1 target of 0 SDS was recommended following analyses of the $\Delta$ HT-SDS/GH dose ratio ${ }^{21}$. In another report by the same author, although the IGF-1 targets were met equally, there was significantly less height gain in ISS children than in GHD children ${ }^{22}$. This suggests that IGF-1 insensitivity or GH insensitivity may be present in ISS children. Therefore, the optimal IGF-1 target for GH treatment in non-GHD subjects needs to be elucidated.

Usually, increased effectiveness of GH therapy is correlated with a younger age at GH therapy initiation, more severe short stature, longer duration of treatment, and higher dosage ${ }^{23)}$. However, the heterogeneous nature of ISS might be related to a variable growth-promoting effect. Sotos and Tokar ${ }^{24)}$ organized their child subjects with ISS into familial and nonfamilial ISS groups, and reported a more favorable adult height gain in the nonfamilial ISS group. A similar result was reported in a Korean study of subjects with familial short stature ${ }^{5}$. We did not classify our ISS subjects into familial and nonfamilial ISS groups; regardless, the study results will be useful for interpreting final height gains in ISS subjects.

There are some limitations to this study. This was not a prospectively designed study comparing the effectiveness of GH treatment between children with ISS and those with IGHD. Rather, this study reported observational results for $1-3$ years of $\mathrm{GH}$ treatment, and we used PAH as an indicator of final adult height. Moreover, our results cannot determine whether the dose regimen used for our ISS children was superior to a higher dose recommended regardless of IGF-1 values. Park and Cohen ${ }^{25)}$ proposed a treatment model that initially used a higher IGF-1 target ( +2 to +3 SDS) in order to increase growth maximally, and followed that high target period by a lower IGF-1 target period for growth maintenance. However, in the present study, we did not adopt this model or the higher dose regimen because ISS includes normal short stature subjects, as well subject safety and treatment cost were of utmost importance. We did not detect any adverse effects related to the dosage we used in both groups. Another limitation of our study is that the numbers of subjects differed in each year of treatment. At the third year of treatment, half of the ISS subjects had dropped from the study, while 73\% of IGHD subjects remained on GH therapy. The dropping of the subjects could bias the mean CA values, although the third year's data were obtained at almost 1 year from the second year's data acquisition time. To compensate for this type of error, the authors used SDS instead of real values.

In conclusion, both ISS and IGHD groups showed significant increases in HT-SDS and approached the genetic MPH-SDS target after 2 to 3 years of GH therapy, respectively. Initially, the lower BA/CA ratio and the lower level of IGF-1 in the IGHD group increased during the first year of therapy, after which those parameters were similar to those in ISS group. The ISS children received a slightly higher GH dose than that given to IGHD children. In the future, larger scaled, long-term studies including the final adult heights are needed to set the appropriate strategies of GH treatment for Korean ISS and GHD subjects.

\section{Conflict of interest}

No potential conflict of interest relevant to this article was reported. 


\section{Acknowledgements}

This work was supported by the intramural research grant of Chungbuk National University in 2015.

\section{References}

1. Korean Society of Pediatric Endocrinology. Pediatric Endocrinology. 3rd ed. Seoul: Gunja Co., 2014:83.

2. Ranke MB. Towards a consensus on the definition of idiopathic short stature. Horm Res 1996;45 Suppl 2:64-6.

3. Cohen P, Rogol AD, Deal CL, Saenger P, Reiter EO, Ross JL, et al. Consensus statement on the diagnosis and treatment of children with idiopathic short stature: a summary of the Growth Hormone Research Society, the Lawson Wilkins Pediatric Endocrine Society, and the European Society for Paediatric Endocrinology Workshop. J Clin Endocrinol Metab 2008;93:4210-7.

4. Loche S, Carta L, Ibba A, Guzzetti C. Growth hormone treatment in non-growth hormone-deficient children. Ann Pediatr Endocrinol Metab 2014;19:1-7.

5. Gubitosi-Klug RA, Cuttler L. Idiopathic short stature. Endocrinol Metab Clin North Am 2005;34:565-80, viii.

6. Kim DH, Shin HJ, Chung SC, Park MJ. Response of growth hormone treatment to final height in children with growth hormone deficiency and familial short stature. J Korean Soc Pediatr Endocrinol 1999;4:159-69.

7. Kang JC, Choi YS, Choi IK, Kim HS, Kim DH. The effect of growth hormone on patients with growth hormone deficiency and idiopathic short stature. Korean J Pediatr 2004;47:310-8.

8. Kim SA, Choe YR, Yang EM, Kim CJ. Comparison of growth hormone treatment in patients with idiopathic short stature and idiopathic growth hormone deficiency. Chonnam Med J 2014;50:63-6.

9. Greulich WW, Pyle SI. Radiographic atlas of skeletal development of the hand and wrist. 2nd ed. Stanford: Stanford University Press, 1959.

10. Bayley N, Pinneau SR. Tables for predicting adult height from skeletal age: revised for use with the Greulich-Pyle hand standards. J Pediatr 1952;40:423-41.

11. Moon JS, Lee SY, Nam CM, Choi JM, Choe BK, Seo JW, et al. 2007 Korean National Growth Charts: review of developmental process and an outlook. Korean J Pediatr 2008;51:1-25.

12. Hyun SE, Lee BC, Suh BK, Chung SC, Ko CW, Kim HS, et al. Reference values for serum levels of insulin-like growth factor-I and insulin-like growth factor binding protein-3 in Korean children and adolescents. Clin Biochem 2012;45:16-21.

13. Growth Hormone Research Society. Consensus guidelines for the diagnosis and treatment of growth hormone (GH) deficiency in childhood and adolescence: summary statement of the GH Research Society. GH Research
Society. J Clin Endocrinol Metab 2000;85:3990-3.

14. Savage MO, Bang P. The variability of responses to growth hormone therapy in children with short stature. Indian J Endocrinol Metab 2012;16(Suppl 2):S178-84.

15. Lee BC, Lee SJ, Jung MH. Final height in growth hormone deficient children treated with growth hormone. J Korean Soc Pediatr Endocrinol 2003;8:27-33.

16. Choi IJ, Hwang JS, Shin CH, Yang SW. Factors affecting on final adult height and total height gain in children with idiopathic and organic growth hormone deficiency after growth hormone treatment. J Korean Pediatr Soc 2003;46:803-10.

17. Kim HS, Yang SW, Yoo HW, Suh BK, Ko CW, Chung WY, et al. Efficacy of short-term growth hormone treatment in prepubertal children with idiopathic short stature. Yonsei Med J 2014;55:53-60.

18. Leschek EW, Rose SR, Yanovski JA, Troendle JF, Quigley CA, Chipman JJ, et al. Effect of growth hormone treatment on adult height in peripubertal children with idiopathic short stature: a randomized, double-blind, placebo-controlled trial. J Clin Endocrinol Metab 2004;89:3140-8.

19. Albertsson-Wikland K, Aronson AS, Gustafsson J, Hagenäs L, Ivarsson SA, Jonsson B, et al. Dose-dependent effect of growth hormone on final height in children with short stature without growth hormone deficiency. J Clin Endocrinol Metab 2008;93:4342-50.

20. McCaughey ES, Mulligan J, Voss LD, Betts PR. Randomised trial of growth hormone in short normal girls. Lancet 1998;351:940-4.

21. Cohen P, Weng W, Rogol AD, Rosenfeld RG, Kappelgaard AM, Germak J. Dose-sparing and safety-enhancing effects of an IGF-I-based dosing regimen in short children treated with growth hormone in a 2 -year randomized controlled trial: therapeutic and pharmacoeconomic considerations. Clin Endocrinol (Oxf) 2014;81:71-6.

22. Cohen P, Germak J, Rogol AD, Weng W, Kappelgaard AM, Rosenfeld RG, et al. Variable degree of growth hormone $(\mathrm{GH})$ and insulin-like growth factor (IGF) sensitivity in children with idiopathic short stature compared with GH-deficient patients: evidence from an IGF-based dosing study of short children. J Clin Endocrinol Metab 2010;95:2089-98.

23. Wit JM, Rekers-Mombarg LT, Cutler GB, Crowe B, Beck TJ, Roberts K, et al. Growth hormone (GH) treatment to final height in children with idiopathic short stature: evidence for a dose effect. J Pediatr 2005; 146:45-53.

24. Sotos JF, Tokar NJ. Growth hormone significantly increases the adult height of children with idiopathic short stature: comparison of subgroups and benefit. Int J Pediatr Endocrinol 2014;2014:15.

25. Park P, Cohen P. The role of insulin-like growth factor I monitoring in growth hormone-treated children. Horm Res 2004;62 Suppl 1:59-65. 